\title{
DEVELOPMENT AND EVALUATION OF A UNIVERSAL CONTOURED CUSHION*
}

\author{
By I. Perkash, M.D., M.S., F.R.C.S., F.R.C.S.E., F.A.C.S., ${ }^{1}$ H. O’Neill, \\ B.S., ${ }^{2}$ D. Politi-MeEks, O.T.R. ${ }^{2}$ and C. L. BeETS, B.S. ${ }^{2}$ \\ ${ }^{1}$ Spinal Cord Injury Service, Veterans Administration Medical Center and Stanford \\ University, Palo Alto, California 94304. ${ }^{2}$ Rehabilitation Engineering Center, \\ Children's Hospital at Stanford, Palo Alto, California 94304.
}

Summary. A new wheelchair seat cushion has been developed which reduces the ischaemia producing forces and redistributes them to the more tolerant areas of the posterior thighs and lateral gluteal muscles. The cushion is fabricated of foam materials and designed to stabilise the pelvis and promote proper spinal-pelvic alignment. Pressure measurements were recorded at the skin cushion interface for 66 subjects while seated on the cushion in their own wheelchair. The cushion was considered effective if maximum interface pressures recorded were: coccyx: $<20 \mathrm{mmHg}$, ischii: $<65 \mathrm{mmHg}$, trochanters: $<70 \mathrm{mmHg}$, and posterior thighs: $<80 \mathrm{mmHg}$. The cushion was considered ineffective if the interface pressure at any one location exceeded these criteria. The cushion was found effective for 52 of the subjects. The cushion was more effective ( 90 per cent versus 58 per cent) for subjects without certain skeletal deformities (pelvic obliquity, bony resections). Eighty-three per cent of the respondents who were followed on the cushion reported that they preferred the cushion to their previous cushions with improved posture, balance and comfort being the most commonly cited reasons. This study has shown the cushion to be a preferred alternative to other commercially available wheelchair cushions for those who are paraplegic.

Key words: Paraplegia; Wheel-chair cushion of new design and new material.

\section{Introduction}

THE GOAL of this project was to develop a mass producible wheelchair cushion which would offer significant protection from pressure sores while providing a stable base for promoting pelvic alignment and trunk stability. The design of the cushion was based upon anatomical data derived from subjects with spinal cord injuries. These data resulted in a cushion which is contoured to facilitate weight bearing over the greatest possible area of the buttocks and posterior thighs. A combination of foam materials was used since they are lighter in weight than gels and provide an inherently more stable sitting base than fluids.

The ability of contoured foam cushions to reduce compressive forces to levels that are well tolerated by the soft tissues of the buttocks is well documented. (Ferguson-Pell, I980; Houle, I969; Key, I979). Contoured cushions were a logical response to the findings of Sweringen (I962) who

* This paper was read at the 1982 Athens Meeting of the International Medical Society of Paraplegia.

This project is supported by a grant from the Veterans Administration Central Office, Rehabilitation Research and Development Service. 
showed that approximately $50 \%$ per cent of the body weight is supported by only eight per cent of the sitting surface, primarily the ischial tuberosities. Reswick and Rogers (1975) subsequently demonstrated that the areas of the sitting surface which ordinarily support little of the load, the subtrochanteric shelf and posterior thighs, are capable of sustaining greater loads than the ischial tuberosities. These findings were incorporated into the design of the Veterans Administration Interface Seating Orthosis (VASIO). The VASIO is a contoured cushion developed for use by paraplegics. The cushion is designed to reduce pressure beneath the ischial tuberosities and transfer the load to the lateral gluteal muscles, subtrochanteric shelf and posterior thighs. The cushion is designed to support the pelvis symmetrically in all planes, thereby diminishing the forces which tend to destabilise the spine. Results of clinical trials and follow-up of 66 subjects using the VASIO are presented.

\section{Development}

The cushion is fabricated from two-part polyurethane foam of two pound density with inserts of Ethafoam-220 to aid in the redistribution of pressure. The cushion is contoured to approximately match the anatomical contours of a large percentage of the spinal cord injury population. The first prototype was developed by taking plaster impressions of the seating area of spinal cord injured individuals and then generating a composite profile. The first models incorporated mushroom-shaped inserts of Ethafoam positioned beneath the proximal thigh. These acted as a fulcrum in an attempt to use the weight of the legs to aid in unweighting the pelvis. The pressures which were generated at this point, however, resulted in decreased circulation in the legs, erythema, and complaints of a burning sensation.

The contours of the cushion and the shape of the inserts have been refined through eight iterations. The inserts are now designed to minimise localised areas of high pressure and to distribute pressures more evenly over the lateral gluteal muscles, subtrochanteric shelf and the posterior thighs. An abduction pommel is incorporated into the cushion to aid in maintaining the hips in proper position. The perineal recess has been deepened to facilitate air flow and aid in controlling humidity and heat retention. The perineal recess is designed to reduce pressure on the urethra and enable air circulation under the perineum.

\section{Methodology}

The cushion is designed to promote a symmetrical sitting posture. A patient selection protocol was therefore established in order to screen those patients with some physical condition which might force an imbalanced sitting posture. The criteria used were: absence of fixed pelvic obliquity, severe scoliosis, lower extremity amputation, ischiectomy or trochanteric resection, dislocated hips and limitation of hip flexion to less than I IO degrees. However, patients who did not meet these criteria were also tested on the cushion in order to gather data to establish a broader selection criteria. Sixty-six patients were tested on the cushion of whom 42 followed and 24 did not follow the foregoing protocol. The effectiveness of the cushion in safely distributing the sitting forces was evaluated by recording the pressure 
at the skin-cushion interface beneath the bony prominences while the patients were seated on the cushion. For comparison, the measurements were repeated with the patients sitting on their own cushions. Patients who had interface pressures less than $80 \mathrm{mmHg}$ beneath the thigh, $70 \mathrm{mmHg}$ beneath the trochanters, $65 \mathrm{mmHg}$ beneath the ischii and $20 \mathrm{mmHg}$ beneath the coccyx were given the option of remaining on the cushion. Slightly higher pessures than those proposed by Reswick and Rogers (I975) were allowed beneath the ischial tuberosities and trochanters. Clinical experience locally has demonstrated that these pressures are well tolerated by most patients. None of the patients in the study developed decubiti or significant redness while using the VASIO. Ferguson-Pell (I980) has reported that similar pressure criteria (6o $\mathrm{mmHg}$ beneath the ischium) were used successfully in the clinic at Glasgow.

During the initial two week period of cushion use those subjects who were inpatients were monitored twice daily by the hospital nursing staff for local redness, erythema or other evidence of soft tissue insult. Pressure measurements were taken again after two weeks in all patients. At this time the patients' subjective comments relative to ease of transfers, stability, posutre, etc. were recorded. The subjective comments were used to evaluate important features of the cushion which could not be otherwise quantified.

Subjects who elected to remain in the study were given the cushion and followed for up to 18 months. Pressure measurements were repeated at three-month intervals and subjective comments again recorded. These data were used primarily to assess the durability of the cushion.

\section{Results}

The mean age of the 66 participants was 4I years (range: 20-65). The mean age of the protocol group was 4I years and the mean age of the non-protocol group was 42 years.

The cushion was found to be effective for $52(79 \%)$ of the 66 subjects based upon the criteria for maximum interface pressure and the absence of persistent soft tissue erythema (Table I). As expected, the rate of effective-

TABLE I

VASIO-P effectiveness (Pressure Measurements)

\begin{tabular}{|c|c|c|c|c|}
\hline A. Proto & $\begin{array}{c}\text { col Patients } \\
\text { Thor } \\
\left(\mathrm{T}_{\mathrm{I}}-\mathrm{T}_{7}\right)\end{array}$ & (T8-TI2) & Lumbar & Total \\
\hline $\begin{array}{l}\text { Subjects } \\
\text { Effective } \\
p= \\
\text { B. Non-P }\end{array}$ & $\begin{array}{l}23 \\
2 \mathrm{I}(9 \mathrm{I} \%) \\
\ll .002 \\
\text { Protocol Patic } \\
\text { Thor } \\
\quad\left(\mathrm{T}_{\mathrm{I}}-\mathrm{T}_{7}\right)\end{array}$ & $\begin{array}{l}\text { I3 } \\
\text { I I }(85 \%) \\
\quad<.02 \\
\text { ents } \\
\text { acic } \\
\text { (T8-Ti2) }\end{array}$ & $\begin{array}{l}6 \\
6(100 \%)\end{array}$ & $\begin{array}{c}42 \\
38(90 \%) \\
<<.002 \\
\text { Total }\end{array}$ \\
\hline $\begin{array}{l}\text { Subjects } \\
\text { Effective } \\
\mathrm{p}=\end{array}$ & $\begin{array}{l}\mathrm{IO} \\
6(60 \%) \\
\quad 1.0\end{array}$ & $\begin{array}{l}\text { I I } \\
6(54 \%) \\
\quad \text { I.0 }\end{array}$ & $\begin{array}{l}3 \\
2(67 \%) \\
<.004\end{array}$ & $\begin{array}{l}24 \\
14(58 \%) \\
\quad<.002\end{array}$ \\
\hline
\end{tabular}




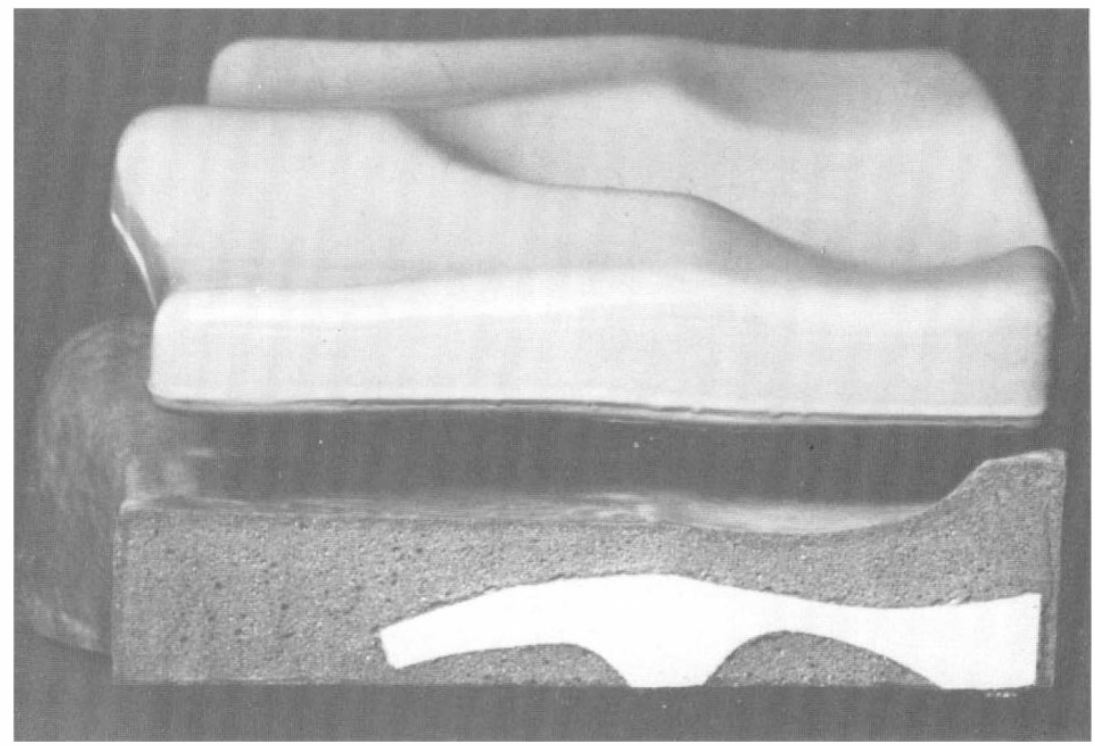

FIG. I

VASIO-PARA Cushions: Commercially Available Version (top) and Research Version (bottom) showing placement and shape of Ethafoam insert.

ness was higher for the protocol group $(90 \%)$ versus the non-protocol group $(58 \%)$.

As set forth in the methodology, two subject groups were established since it was anticipated that the cushion would be less effective for those with skeletal deformities. These deformities typically force an imbalanced sitting posture which is reflected in an asymmetric distribution of interface pressure over the sitting surface. Assymetric pressure distribution is defined as a difference in the measured pressure beneath corresponding anatomical locations (trochanter-trochanter, ischium-ischium). Asymmetric distributions were observed in both groups; however, the nonprotocol group exhibited both a greater incidence and higher magnitude of difference pressure than the protocol group.

At a difference in interface pressure of $20 \mathrm{mmHg}$ or greater, the incidence was twice as great in the non-protocol group versus the protocol group $(7 \mathrm{I} \%$ versus $36 \%$ ). At a difference of $30 \mathrm{mmHg}$ or greater, the incidence rose to over four times higher for the non-protocol group compared to the protocol group ( $54 \%$ versus $12 \%$ ).

A composite of interface pressures for the VASIO-P compared to three other commonly used cushions is shown in Figure 2. The graphs show that the VASIO-P effectively redistributes the forces away from the ischial tuberosities and onto the posterior thighs and trochanters. In 62 cases a Scimedics pressure gauge failed to register any pressure beneath the coccyx exceeding $20 \mathrm{mmHg}$ (typically zero). Four of the 66 subjects did exhibit pressure beneath the coccyx which exceeded $20 \mathrm{mmHg}$. Two of these were in the protocol group $(24 \mathrm{mmHg}, 27 \mathrm{mmHg}$ ) and two were in the non-protocol group $(30 \mathrm{mmHg}, 42 \mathrm{mmHg}$ ). 


\section{VASIO CUSHION STUDY}
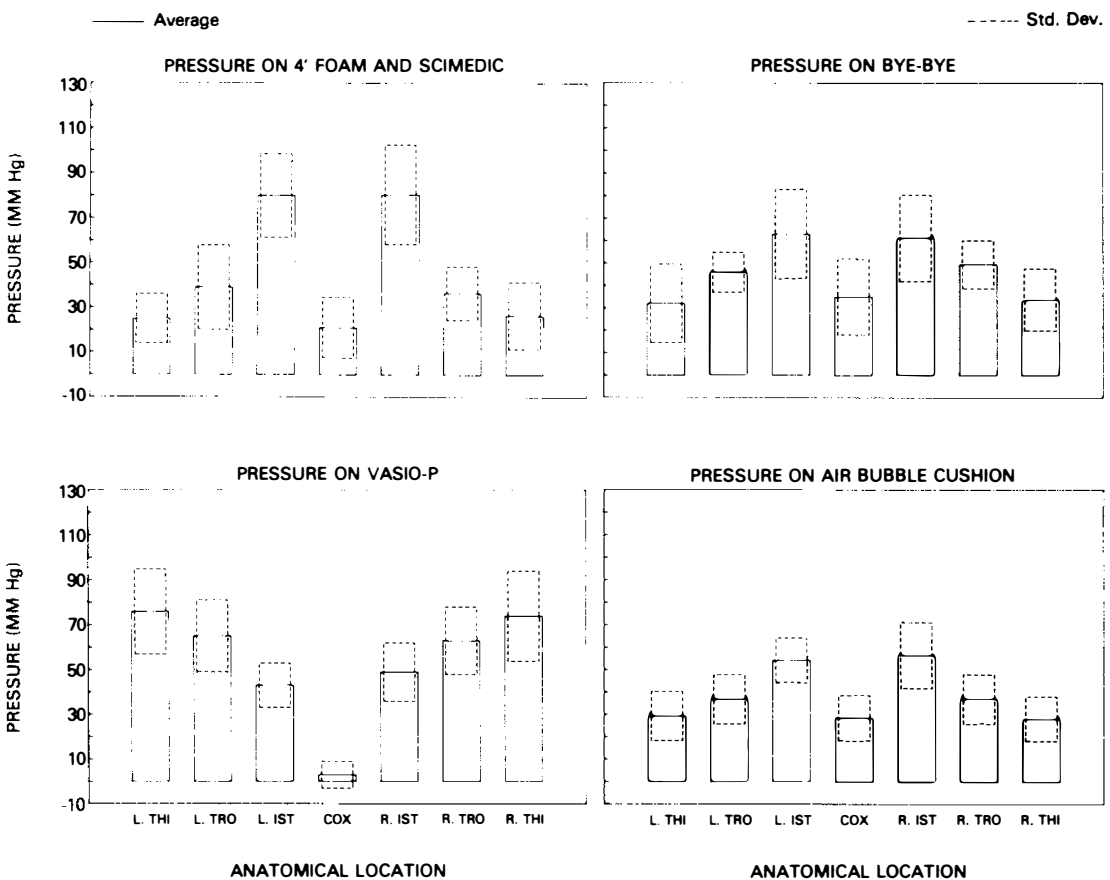

FIG. 2

Comparison of Pressure Distribution Characteristics of VASIO Cushion and Commonly Used Commercial Cushions.

All subjects were asked to rate the VASIO-P relative to their previous cushion. The responses are shown in Table II. The only significant negative comment reported was increased difficulty in transferring on and off the cushion due to the height of the abduction pommel and the overall

TABLE II

Subjective responses ( $\%$ of respondents)

\begin{tabular}{lccc}
\hline & Improved & No change & Worse \\
\cline { 2 - 4 } Posture & 83 & 13 & 4 \\
Balance & 60 & 30 & I0 \\
Comfort & 65 & 22 & 13 \\
Practicality & 62 & 14 & 24 \\
Durability & 81 & 19 & 0 \\
Ventilation & 63 & 25 & I2 \\
W/C propulsion & 33 & 45 & 22 \\
Cleanliness & 45 & 50 & 5 \\
Sitting times & 39 & 48 & 13 \\
Temperature & 4 & 70 & 26 \\
Transfers & 24 & 10 & 66 \\
General favourability & 83 & 9 & 8 \\
\hline
\end{tabular}


thickness of the cushion. Only one patient rejected the cushion due to difficulty in transferring; the others felt that its advantages outweighed the disadvantage. Overall, 83 per cent of the respondents reported that they preferred the VASIO-P over their previous cushions.

\section{Discussion}

The goal of this project was to develop a wheelchair cushion which would redistribute the ischaemia producing forces away from the osseous points and onto the more tolerant areas of the subtrochanteric shelf and posterior thighs. In contrast to flotation type cushions the VASIO-P was designed to provide a stable base to improve balance and minimise pelvic/spinal malalignment. The results show that the cushion is effective in relieving pressure and an immediate improvement in posture and balance has been observed with most subjects, particularly in those who have been using flotation type cushions.

The high rate of effectiveness $(79 \%)$ of the VASIO is a notable improvement over other types of cushion, particularly those which provide comparable pelvic stabilisation. For comparison, the same criteria for acceptable pressure levels were applied to 25 pressure tests on 4 " foam cushions extracted from patient records and it was found that none of the patients had acceptable pressure readings. Only I 6 per cent of the patients had ischial readings $<65 \mathrm{mmHg}$. The same criteria were applied to the pressure measurements recorded with 25 patients on ROHO cushions. In these test cases sub-ischial pressures were within acceptable limits in 80 per cent of the patients but sacrococcygeal pressures were high $(76 \%>20$ $\mathrm{mmHg}, 52 \%>30 \mathrm{mmHg}$ ).

The high percentage of effectiveness within the protocol group relative to the non-protocol group supports the patient selection criteria as valid predictors of cushion performance. The cushion was effective for 90 per cent of those in the protocol group as compared to 58 per cent of those in the non-protocol group. This difference results from skeletal deformities which originally caused these subjects to be eliminated from the protocol group. Nine of the ten subjects in the non-protocol group for whom the cushion was found ineffective exhibited asymmetric pressure readings (difference pressure $>20 \mathrm{mmHg}$ ) which were the result of their deformities. Although asymmetric pressure distributions also occurred within the protocol group, the magnitude was less and not a factor in cushion effectiveness for this population. None of the four patients in the protocol group for whom the cushion was ineffective exhibited asymmetric pressure distribution.

There was no measurable cause for the asymmetric pressures noted in the protocol group. Postural habits, such as leaning to one side or sitting closer to one side in the wheelchair will often be reflected in an asymmetric pressure distribution. Similarly, muscle imbalance or other less obvious physiological factors may also help to explain the findings. Whatever the causes; their impact on cushion effectiveness is considerably less than that caused by skeletal deformities.

The VASIO-P, as with any contoured cushion, requires that the user sit symmetrically in the centre of the cushion. The suitability of this type of cushion for any individual must be determined partly by their ability to 
take responsibility for positioning themselves, or being positioned, properly on the cushion. This cushion is not recommended for tetraplegic patients since muscle spasms or rough terrain may alter the patient's position on the cushion. In such a case, the individual would be unable to resposition himself properly on the cushion.

The cushion was tested primarily with adult spinal cord injured males, ( 2 females). The cushion was found to be effective with both female subjects and they continued to be followed up as part of the protocol group. The results of the clinical evaluation have shown that the cushion is effective in accommodating the pelvic structure of 79 per cent (90 per cent when skeletal deformities are screened) of the subjects tested by redistributing the sitting forces and reducing pressures to tolerable levels. Females now account for I 8 per cent (Young, I982) of the spinal cord injured population. Because of the greater bi-ischial dimension in the female pelvis (Roule, I969) additional testing will need to be performed to determine whether the contours now in use will be equally valid for females.

It is commonly noted in the clinic that many patients who are using flotation type cushions (air, water, etc.) develop an obvious pelvic obliquity within a short time after being placed on the cushion. Although most patients learn to take the poor posture and impaired balance for granted, many when placed on the VASIO, reported an improvement in posture and in balance.

The improvements in posture, balance, comfort and practicality have proven to be the most desirable features of the VASIO-P. Subjects reported that these improvements result in greater ease for travelling over rough terrain, wheelchair manipulation and enhancement of two-handed and table top activities. We hope to see a long-term benefit of minimising pelvic/ spinal malalignment and related biomechanical sequelae.

To date the feature of the abduction pommel has elicited a consistently negative comment, primarily related to difficulties in transferring. This has been resolved in the commercial version* of the cushion by decreasing the height of the pommel.

\title{
Conclusion
}

The VASIO-P has been shown to be effective in redistributing the sitting forces to acceptable levels with the great majority $(79 \%)$ of paraplegics in the spinal cord injured population.

\begin{abstract}
RÉSUMÉ
On a développé un coussin pour chaise roulante qui réduit les poids causant l'ischimie, en les redistribuant vers les surfaces moins fragiles des cuisses et de la région latérale des muscles fessiers. Ce coussin, fabriqué en mousse synthétique est construit de sorte à stabiliser le bassin et à réaligner le pelvis et la colonne vertébrale. On a mesuré la tension entre la peau et le coussin chez 66 patients assis sur leur propre chaise roulante. Le coussin était considéré efficace si la tension maximum entre la peau et le coussin était: coccyx: $<20$ $\mathrm{mmHg}$, ischii: $<65 \mathrm{mmHg}$, trochanters: $<70 \mathrm{mmHg}$, et cuisses postérieures: $<80 \mathrm{mmHg}$. Le coussin était considéré inefficace si la tension entre la peau et le coussin était supérieure à ces taux en un seul endroit. Les résultats ont été satisfaisants pour 52 patients. Il s'est avéré plus efficace $(90 \%$ vs $58 \%$ ) pour les patients sans difformité osseuse. $83 \%$ des patients
\end{abstract}

* The VASIO-PARA is available through J. A. Preston Corp. 
ont déclaré qu'ils préféraient ce coussin à ceux qu'ils avaient, donnant comme raison principale son confort et le fait qu'il améliore la posture et l'équilibre.

Cette étude a prouvé que ce coussin est la meilleure alternative sur le marché de l'équipement pour paraplégiques.

\section{ZUSAMMENFASSUNG}

Wir berichten ueber die Entwicklung eines neuen Rollstuhl-Sitzkissens. Es reduziert die Ischaemie hervorrufenden Kraefte und fuehrt sie den belastbareren Gebieten der hinteren Oberschenkel und lateralen glutealen Muskeln zu. Das Kissen ist aus Schaumstoff hergestellt und so konstruiert, dass es das Becken stabilisiert und die richtige RueckgratBecken-Position gewaehrleistet. Bei 66 Versuchspersonen wurde die Druckverteilung an der Kontaktflaeche zwischen Haut und Sitzkissen gemessen, waehrend sie darauf in ihrem eigenen Rollstuhl sassen. Um das Kissen als geeignet zu betrachten, wurde als maximaler Uebergangsdruck festgelegt: Fuer die Coccyx $<20 \mathrm{mmHg}$, fuer die Ischii $<65 \mathrm{mmHg}$, fuer die Trochanter $<70 \mathrm{mmHg}$ und fuer die hinteren Oberschenkel $<80 \mathrm{mmHg}$. Wenn der Uebergangsdruk an einer der Positionen diese Kriterien ueberschritt, wurde das Kissen als ineffektiv betrachtet. Bei 52 der Probanden erwies sich das Sitzkissen als geeignet. Es war effektiver $\left(90 \%\right.$ versus $58^{\circ}$ ) bei Personen ohne bestimmte Skelettdeformationen (Beckenschiefe, Knochenresektion). In einer Nachuntersuchung berichteten $83 \%$ der Antwortenden, dass sie das neue Kissen ihrem vorigen vorzoegen. Dabei waren verbesserte Position, Gleichgewicht und Bequemlichkeit die am haeufigsten angefuehrten Gruende. Insgesamt erwies sich das untersuchte Kissen als Alternative der Wahl im Vergleich zu anderen im Handel erhaeltlichen Rollstuhl-Sitzkissen fuer Paraplegiker.

\section{REFERENCES}

Ferguson-Pell, M., et al. (1980). Pressure Sore Prevention for the Wheelchair-Bound Spinal Injury Patient. Paraplegia, 18, 42-5I.

Houle, R. (I969). Evaluation of Seat Devices to Prevent Ischemic Ulcers in Paraplegic Patients. Archives of Physical Medicine and Rehabilitation, 50, 587-594.

Key, A., Manley, M. \& Wakefield, E. (I978-79). Pressure Redistribution in Wheelchair Cushion for Paraplegics: Its Application and Evaluation. Paraplegia, 16, 403-4I2.

Reswick, J. \& Rogers, J. (I975). Tissue Trauma Group, Annual Report of Progress, Rancho Los Amigos Hospital, pp. 24-3I.

SweARINGEN, J., et al. (1962). An Analysis of Sitting Areas and Pressures of Man. Oklahoma City, Federal Aviation Administration.

Young, J. S., Burns, P. E., Bowen, A. M. \& McCutcheon, R. (I982). Spinal Cord Injury Statistics-Experience of the Regional Spinal Cord Injury Systems, Good Samaritan Medical Center, Phoenix, Arizona. 